\title{
The C242T polymorphism of the p22-phox gene (CYBA) is associated with higher left ventricular mass in Brazilian hypertensive patients
}

\author{
Roberto Schreiber ${ }^{1}$, Maria C Ferreira-Sae ${ }^{1}$, Juliana A Ronchi ${ }^{2}$, José A Pio-Magalhães ${ }^{1}$, José A Cipolli ${ }^{1}$, \\ José R Matos-Souza ${ }^{1}$, José G Mill ${ }^{3}$, Aníbal E Vercesi ${ }^{2}$, José E Krieger ${ }^{4}$, Kleber G Franchini $^{1}$, Alexandre C Pereira ${ }^{4}$ and \\ Wilson Nadruz Junior ${ }^{1 *}$
}

\begin{abstract}
Background: Reactive oxygen species have been implicated in the physiopathogenesis of hypertensive end-organ damage. This study investigated the impact of the C242T polymorphism of the p22-phox gene (CYBA) on left ventricular structure in Brazilian hypertensive subjects.

Methods: We cross-sectionally evaluated 561 patients from 2 independent centers [Campinas $(n=441)$ and Vitória $(n=120)]$ by clinical history, physical examination, anthropometry, analysis of metabolic and echocardiography parameters as well as p22-phox C242T polymorphism genotyping. In addition, NADPH-oxidase activity was quantified in peripheral mononuclear cells from a subgroup of Campinas sample.

Results: Genotype frequencies in both samples were consistent with the Hardy-Weinberg equilibrium. Subjects with the $T$ allele presented higher left ventricular mass/height ${ }^{2.7}$ than those carrying the CC genotype in Campinas (76.8 \pm 1.6 vs $70.9 \pm 1.4 \mathrm{~g} / \mathrm{m}^{2.7} ; p=0.009$ ), and in Vitória ( $45.6 \pm 1.9$ vs $39.9 \pm 1.4 \mathrm{~g} / \mathrm{m}^{2.7} ; p=0.023$ ) samples. These results were confirmed by stepwise regression analyses adjusted for age, gender, blood pressure, metabolic variables and use of anti-hypertensive medications. In addition, increased NADPH-oxidase activity was detected in peripheral mononuclear cells from T allele carriers compared with CC genotype carriers ( $p=0.03)$.

Conclusions: The T allele of the p22-phox C242T polymorphism is associated with higher left ventricular mass/ height ${ }^{2.7}$ and increased NADPH-oxidase activity in Brazilian hypertensive patients. These data suggest that genetic variation within $\mathrm{NADPH}$-oxidase components may modulate left ventricular remodeling in subjects with systemic hypertension.
\end{abstract}

Keywords: p22-phox, left ventricle, hypertension, polymorphism, NADPH-oxidase

\section{Background}

Left ventricular (LV) hypertrophy is an independent predictor of cardiovascular events and is a major risk factor for the development of heart failure in hypertensive subjects [1]. Oxidative stress derived from Nicotinamide adenine dinucleotide phosphate (NADPH)-oxidase has been implicated in the physiopathogenesis of hypertensive LV remodeling [2,3]. Among the subunits that comprise the NADPH-oxidase system, the p22-phox is highlighted as an essential membrane-associated factor that plays a

\footnotetext{
* Correspondence: wilnj@fcm.unicamp.br

'Department of Internal Medicine, University of Campinas, Campinas, Brazil Full list of author information is available at the end of the article
}

crucial role in the activation and stabilization of this enzymatic complex [4]. In this regard, experimental evidence showed that LV hypertrophy is accompanied by increased myocardial p22-phox expression in aorticbanded rats, suggesting that this protein might be involved in hypertensive cardiac remodeling [2,5].

To date, several polymorphisms of the p22-phox gene (CYBA) have been identified [6]. One of the most studied polymorphisms of this gene is the $\mathrm{C} 242 \mathrm{~T}$, which predicts the nonconservative substitution of histidine- 72 by a tyrosine residue [7] and has been shown to enhance the functional activity of NADPH-oxidase [8]. However, although numerous studies investigated the role of the

\section{C) Biomed Central}


p22-phox C242T polymorphism in cardiovascular phenotypes [9], a significant heterogeneity for a modulating role of the $\mathrm{T}$ allele has been reported $[9,10]$. In addition, little is known about the impact of this variant on the development of hypertensive end-organ damage. Thus, the aim of the present report was to investigate whether the C242T p22-phox polymorphism is associated with variation in LV structure in hypertensive subjects.

\section{Methods}

\section{Study population}

The study was carried out in 561 unrelated hypertensive subjects from two independent centers located in distinct states of Brazil. The Campinas sample consisted of hypertensive patients from a tertiary referral clinic hospital and comprised 441 subjects (264 women and 177 men) from the city of Campinas, São Paulo State, with high prevalence of end-organ damage $[11,12]$. The Vitória sample consisted of hypertensive patients from a populationbased study and comprised 120 subjects (76 women and 44 men) from the city of Vitória, Espírito Santo State [13]. The research was carried out in accordance with the Declaration of Helsinki of the World Medical Association. This study was approved by the Human Research Ethics Committee of the University of Campinas and by the Committee for Research on Human Subjects of the Espírito Santo Federal University. All subjects gave written informed consent to participate.

Hypertension was defined as systolic blood pressure $\geq 140 \mathrm{mmHg}$ or diastolic blood pressure $\geq 90 \mathrm{mmHg}$ or current antihypertensive medication use. Diabetes mellitus was diagnosed if fasting blood glucose was $\geq 126 \mathrm{mg} / \mathrm{dL}$ or when participants were taking hypoglycemic medications [14]. Coronary heart disease was diagnosed by history of myocardial infarction, acute coronary syndrome or coronary revascularization or by evidence of cardiac ischemia documented by functional testing. Main exclusion criteria were age under 18 years, significant cardiac valve disease, hypertrophic cardiomyopathy and neoplastic disease.

Blood pressure was measured using a validated digital oscillometric device (HEM-705CP; Omron Healthcare, Kyoto, Japan) with appropriate cuff sizes. Two readings were averaged and, if they differed by more than $5 \mathrm{mmHg}$, one additional measurement was performed and the average of the three measurements was taken.

Body mass index was calculated as body weight divided by height squared $\left(\mathrm{kg} / \mathrm{m}^{2}\right)$. Fasting blood total cholesterol, low-density-lipoprotein cholesterol, highdensity-lipoprotein cholesterol, triglycerides, uric acid and glucose levels were measured using standard laboratory techniques. In addition, creatinine clearance was calculated from serum and urine samples.

\section{Echocardiography}

Echocardiography studies were performed on each subject at rest in the left lateral decubitus position using a Vivid 3 Pro (General Electric, Milwaukee, WI) apparatus equipped with a $2.5 \mathrm{MHz}$ transducer as previously described $[15,16]$. LV end-diastolic and end-systolic diameters, interventricular septum thickness, posterior wall thickness and LV mass were measured in accordance with the American Society of Echocardiography guidelines [17]. Relative wall thickness was computed as twice the posterior wall thickness divided by LV end-diastolic diameter. LV mass index was considered as LV mass/ height $^{2.7}$. All the recordings were made by one physician in the Campinas sample and by another physician in the Vitória sample. The reproducibility of both acquiring and measuring LV mass was determined in recordings obtained from 10 subjects in each sample. Intraobserver and interobserver LV mass variabilities were $<8 \%$ and $<$ $11 \%$, respectively.

\section{Genotyping}

Genomic DNA was extracted from peripheral blood leukocytes. The p22-phox C242T polymorphism was analyzed by polymerase chain reaction and digestion with Rsa-I restriction enzyme [18]. Quality control for these assays was assessed by randomly selecting 40 samples to be re-genotyped by two independent technicians.

\section{NADPH-oxidase activity assay}

NADPH-oxidase activity was assessed in peripheral mononuclear cells (monocytes and lymphocytes) isolated from blood samples according to Degasperi et al. [19]. Briefly, peripheral blood monocytic cells from 18 hypertensive patients of the Campinas sample carrying different p22-phox C242T genotypes (6 CC, 6 CT and 6 TT subjects) were isolated by density gradient centrifugation over Histopaque 1077 and washed twice with phosphate-buffered saline. Cells were counted in a Neubauer chamber, and cell viability was determined by trypan blue exclusion method. Cells were only used when viability was greater than $98 \%$. In order to evaluate NADPHoxidase activity, dihydroethidium (DHE) (Molecular Probes Inc., Eugene, OR) was used as a sensitive probe. For this purpose, cells $\left(2 \times 10^{6}\right.$ cells $\left./ \mathrm{mL}\right)$ were immediately incubated with $10 \mu \mathrm{M} \mathrm{DHE}$ at $37^{\circ} \mathrm{C}$, with or without $10 \mu \mathrm{M}$ diphenylene iodonium (DPI), a selective inhibitor of NADPH-oxidase, and the fluorescence intensity was quantified in a spectrofluorometer (F-4500, Hitachi, Tokyo, Japan) using excitation and emission wavelengths of 563 and $587 \mathrm{~nm}$, respectively, and slit widths of $5 \mathrm{~nm}$, with gentle continuous stirring. The difference between the activities measured without and with DPI was considered as NADPH-oxidase activity. 


\section{Statistical analysis}

Data were analyzed using SPSS $15.0^{\mathrm{TM}}$. Descriptive statistical results are given as means \pm SEM. The differences in genotype distributions, categorical variables as well as Hardy-Weinberg disequilibria for polymorphism were tested using chi-square test. Unpaired t-test was used to compare continuous variables and to evaluate differences in NADPH-oxidase activity between genotype groups. Stepwise regression analyses evaluated the independent predictors of LV mass index. A $p$-value of less than 0.05 was considered significant.

\section{Results}

\section{Distribution and allele frequency of polymorphism}

The distribution of genotypes and the frequency of alleles of the polymorphism $\mathrm{C} 242 \mathrm{~T}$ of the p22-phox gene are summarized in Table 1. The allele frequencies in both samples obeyed the Hardy-Weinberg's law. There was no significant difference in the genotype distribution between Campinas and Vitória samples $\left(X^{2}=1.6815 ; p=0.4314\right)$.

\section{Sample characteristics}

The clinical and laboratory characteristics of hypertensive subjects in both samples according to the C242T polymorphism are shown in Table 2. Given the described dominant effect of the $\mathrm{T}$ allele in functional and association studies $[8,20-22]$ and in order to enhance statistical power, TT subjects were added to CT ones. No differences regarding the clinical and laboratory features were detected between the genotype groups in both samples, except for higher diabetes mellitus prevalence and glucose levels in Campinas CT+TT subgroup and higher height in Vitória CC group.

Association of the C242T polymorphism with LV structure Echocardiography data are demonstrated in Table 3. Hypertensive subjects carrying the $\mathrm{T}$ allele of the $\mathrm{C} 242 \mathrm{~T}$ polymorphism presented higher LV mass/height ${ }^{2.7}$ than those with the CC genotype in both samples. In addition subjects from the Campinas sample with the $\mathrm{T}$ allele exhibited higher posterior wall thickness and LV enddiastolic diameter, compared to CC genotype carriers.

Considering that the relationships between the C242T polymorphism and LV mass/height ${ }^{2.7}$ could be influenced

$\begin{aligned} & \text { Table } 1 \text { p22-phox C242T polymorphism in patients with } \\
& \text { hypertension }\end{aligned}$
\begin{tabular}{lccl}
\hline Genotype & Campinas, $\mathbf{n}(\%)$ & Vitória, $\mathbf{n}(\%)$ & \\
\hline$T$ & $60(13.6)$ & $11(9.2)$ & \\
$C T$ & $189(42.8)$ & $54(45.0)$ & \\
$C C$ & $192(43.6)$ & $55(45.8)$ & \\
T Allele frequency & 0.35 & 0.32 & $\mathrm{p}=0.431$ \\
C Allele frequency & 0.65 & 0.68 & $\mathrm{X}^{2}=1.681$ \\
\hline
\end{tabular}

by potential confounders, stepwise regression analyses were performed (Table 4). The $242 \mathrm{~T}$ allele was independently related to LV mass/height ${ }^{2.7}$ in both samples by using a model that included gender, age, body mass index, systolic blood pressure, diastolic blood pressure, p22-phox C242T polymorphism, diabetes mellitus, calcium channel blockers use and angiotensin-converting enzyme inhibitors/angiotensin receptor blockers use as independent variables.

\section{Relationship between NADPH-oxidase activity and the C242T polymorphism}

To investigate the effects of the polymorphism on the NADPH-oxidase activity, we used DHE as a sensitive probe to evaluate superoxide anion production in peripheral blood mononuclear cells from 18 hypertensive patients of the Campinas sample (Figure 1). Mononuclear cells from subjects with the $T$ allele $(n=12)$ presented higher NADPH-oxidase activity $(\mathrm{p}=0.03)$ than those from individuals carrying the $\mathrm{CC}$ genotype $(\mathrm{n}=6)$.

\section{Discussion}

Experimental evidence has indicated that activation of the $\mathrm{NADPH}$-oxidase plays a major role in the development of LV hypertrophy induced by pressure overload $[2,3]$. In the present report we found that the p22-phox C242T variant was independently associated with higher LV mass index in hypertensive subjects from 2 distinct Brazilian populations. Furthermore, in vitro assays demonstrated that peripheral blood mononuclear cells of $\mathrm{T}$ allele carriers presented higher NADPH-oxidase activity, compared to non-carriers. Taken together, these findings suggest that a functional p22-phox polymorphism is associated with alterations in LV mass in hypertensive subjects, thus extending to humans the notion that variation in NADPH-oxidase activation might influence LV remodeling induced by pressure overload.

Several studies investigated the role of the p22-phox $\mathrm{C} 242 \mathrm{~T}$ polymorphism in cardiovascular phenotypes. However, a significant heterogeneity for a modulating role of the $\mathrm{T}$ allele in the occurrence of atherothrombotic disease and hypertension has been reported $[9,10]$. In this context, carriers of the $242 \mathrm{~T}$ allele were reported to be more susceptible to coronary artery disease [20], cerebrovascular disease [21] and hypertension [22], while other groups described neutral or even protective effects of this variant against such conditions [23-26]. Conversely, the role of the C242T polymorphism as well as of other p22phox variants in the development of hypertensive endorgan damage is poorly understood. Previous data from our group demonstrated that the -930AG polymorphism of the p22-phox was not associated with alterations in LV structure and renal damage in Brazilian hypertensive subjects [27]. In the present report, we provided novel 
Table 2 Characteristics of hypertensive subjects according to the C242T polymorphism

\begin{tabular}{|c|c|c|c|c|c|c|}
\hline \multirow{2}{*}{$\frac{\text { Variable }}{\text { Genotype (N) }}$} & \multicolumn{2}{|c|}{ Campinas } & \multirow[t]{2}{*}{$p$} & \multicolumn{2}{|c|}{ Vitória } & \multirow[t]{2}{*}{$p$} \\
\hline & $C T+\Pi(249)$ & CC (192) & & $C T+\Pi(65)$ & CC (55) & \\
\hline Age, years & $57.2 \pm 0.8$ & $56.4 \pm 0.9$ & 0.573 & $54.2 \pm 1.2$ & $57.3 \pm 1.2$ & 0.078 \\
\hline Gender (M/F) & $101 / 148$ & $76 / 116$ & 0.912 & $20 / 45$ & $24 / 31$ & 0.205 \\
\hline Weight, kg & $80 \pm 1$ & $77 \pm 1$ & 0.075 & $80 \pm 1$ & $80 \pm 2$ & 0.727 \\
\hline Height, cm & $160 \pm 1$ & $159 \pm 1$ & 0.318 & $158 \pm 1$ & $161 \pm 1$ & 0.015 \\
\hline Body mass index, $\mathrm{kg} / \mathrm{m}^{2}$ & $31.5 \pm 0.3$ & $30.6 \pm 0.4$ & 0.118 & $31.9 \pm 0.4$ & $30.9 \pm 0.5$ & 0.143 \\
\hline Systolic BP, mmHg & $148 \pm 1$ & $146 \pm 1$ & 0.457 & $143 \pm 2$ & $144 \pm 2$ & 0.702 \\
\hline Diastolic BP, mmHg & $85 \pm 1$ & $86 \pm 1$ & 0.762 & $91 \pm 2$ & $94 \pm 2$ & 0.359 \\
\hline Diabetes mellitus, n (\%) & $81(32)$ & $40(21)$ & 0.008 & $10(15)$ & $6(11)$ & 0.653 \\
\hline Smokers, n (\%) & $25(10)$ & $21(11)$ & 0.885 & $14(21)$ & $7(13)$ & 0.305 \\
\hline Coronary heart disease, n (\%) & $36(14)$ & $34(18)$ & 0.426 & $2(3)$ & $2(4)$ & 0.864 \\
\hline LDL-cholesterol, mg/dL & $112 \pm 2$ & $112 \pm 2$ & 0.829 & $124 \pm 5$ & $117 \pm 4$ & 0.291 \\
\hline HDL-cholesterol, mg/dL & $51 \pm 1$ & $52 \pm 1$ & 0.748 & $43 \pm 1$ & $45 \pm 1$ & 0.401 \\
\hline Triglycerides, mg/dL & $162 \pm 6$ & $148 \pm 6$ & 0.100 & $195 \pm 13$ & $182 \pm 13$ & 0.501 \\
\hline Glucose, mg/dL & $116 \pm 3$ & $106 \pm 3$ & 0.030 & $117 \pm 6$ & $106 \pm 6$ & 0.184 \\
\hline Uric acid, mg/dL & $5.9 \pm 0.1$ & $6.1 \pm 0.1$ & 0.344 & $5.5 \pm 0.1$ & $5.4 \pm 0.1$ & 0.779 \\
\hline Creatinine clearance rate, $\mathrm{mL} / \mathrm{min}$ & $88 \pm 2$ & $91 \pm 2$ & 0.409 & $88 \pm 4$ & $86 \pm 4$ & 0.733 \\
\hline Diuretics, n (\%) & $188(75)$ & $154(80)$ & 0.289 & $26(40)$ & $25(45)$ & 0.676 \\
\hline Calcium channel blockers, n (\%) & $124(50)$ & $97(51)$ & 0.956 & $8(12)$ & $7(13)$ & 0.944 \\
\hline Beta-Blockers, n (\%) & $117(47)$ & $86(45)$ & 0.717 & $15(23)$ & $13(24)$ & 0.942 \\
\hline ACEI or ARB, n (\%) & $191(77)$ & $153(79)$ & 0.526 & $32(49)$ & $19(34)$ & 0.151 \\
\hline
\end{tabular}

BP - blood pressure; LDL - low-density lipoprotein; HDL - high-density lipoprotein; ACEI or ARB - angiotensin-converting enzyme inhibitors or angiotensin receptor blockers.

evidence that the C242T polymorphism was associated with higher LV mass index in hypertensive patients independently of potential confounding factors such as age, gender, blood pressure, metabolic variables and use of anti-hypertensive medications. Noticeably these findings were reproduced in 2 independent and unrelated samples, with quite different clinical features, thus strengthening the validity of the results. In this regard, the Campinas sample comprised subjects with high prevalence of end-organ damage who attended a tertiary hospital, while the Vitória sample included individuals from a population-based study. On the other hand, given that our functional assays demonstrated higher NADPHoxidase activity in mononuclear cells carrying the $\mathrm{T}$ allele, it can be speculated that functional genetic variation in NADPH-oxidase components may modulate LV remodeling in hypertensive patients. Nevertheless, it cannot be discarded that the $\mathrm{C} 242 \mathrm{~T}$ polymorphism is in linkage disequilibrium with another functional polymorphism, located in the same gene or in its vicinity.

The present study showed that NADPH-oxidase activity of mononuclear cells with the $\mathrm{T}$ allele was higher than that of mononuclear cells without the $\mathrm{T}$ allele, which indicates that the $\mathrm{C} 242 \mathrm{~T}$ polymorphism of $\mathrm{p} 22$ phox might lead to gain of function for the NADPHoxidase activity. Other reports previously assessed the functional role of this polymorphism in leukocyte NADPH-oxidase activity, but yielded conflicting results. For instance, studies using phorbol 12-myristate 13acetate (PMA) stimulation have demonstrated either increased [8] or reduced [26,28] NADPH-oxidase activity in leucocytes carrying the $\mathrm{T}$ allele. The reasons for such discrepancies are not apparent but it is possible that differences in clinical and ethnical features among

Table 3 Echocardiographic features of hypertensive patients according to the C242T polymorphism

\begin{tabular}{|c|c|c|c|c|c|c|}
\hline \multirow{2}{*}{$\begin{array}{l}\text { Variable } \\
\text { Genotype (N) }\end{array}$} & \multicolumn{2}{|c|}{ Campinas } & \multirow[t]{2}{*}{$p$} & \multicolumn{2}{|c|}{ Vitória } & \multirow[t]{2}{*}{$p$} \\
\hline & $C T+\Pi(249)$ & CC (192) & & $C T+T T(65)$ & CC (55) & \\
\hline Interventricular septum, mm & $10.9 \pm 0.1$ & $10.7 \pm 0.1$ & 0.089 & $9.1 \pm 0.1$ & $8.8 \pm 0.1$ & 0.141 \\
\hline Posterior wall thickness, mm & $10.9 \pm 0.1$ & $10.5 \pm 0.1$ & 0.010 & $8.8 \pm 0.1$ & $8.7 \pm 0.1$ & 0.402 \\
\hline LV end-diastolic diameter, mm & $50.9 \pm 0.4$ & $49.7 \pm 0.4$ & 0.047 & $48.8 \pm 0.7$ & $47.8 \pm 0.6$ & 0.272 \\
\hline Relative wall thickness & $0.433 \pm 0.004$ & $0.425 \pm 0.005$ & 0.387 & $0.364 \pm 0.005$ & $0.362 \pm 0.006$ & 0.825 \\
\hline LV Mass/height ${ }^{2.7}, \mathrm{~g} / \mathrm{m}^{2.7}$ & $76.8 \pm 1.6$ & $70.9 \pm 1.4$ & 0.009 & $45.6 \pm 1.9$ & $39.9 \pm 1.4$ & 0.023 \\
\hline
\end{tabular}

LV - left ventricular. 
Table 4 Stepwise regression analyses for LV mass index $\left(\mathrm{g} / \mathrm{m}^{2.7}\right)$

\begin{tabular}{|c|c|c|c|c|}
\hline Step & Variable & $\mathrm{R}^{2}$ Change & F Ratio & $P$ \\
\hline & Model 1: Campinas sample & & & \\
\hline 1 & Body mass index & 0.086 & 41.0 & $<0.00001$ \\
\hline 2 & Age & 0.040 & 19.7 & 0.00001 \\
\hline 3 & p22-phox C242T (CC = 0; CT+TT = 1) & 0.011 & 4.8 & 0.029 \\
\hline \multirow[t]{2}{*}{4} & Systolic blood pressure & 0.010 & 4.5 & 0.036 \\
\hline & Model 2: Vitória sample & & & \\
\hline 1 & Gender & 0.067 & 8.5 & $<0.004$ \\
\hline 2 & Diastolic blood pressure & 0.036 & 4.7 & 0.032 \\
\hline 3 & p22-phox C242T (CC = 0; CT+TT = 1) & 0.032 & 4.3 & 0.041 \\
\hline
\end{tabular}

Both models included gender, age, body mass index, systolic blood pressure, diastolic blood pressure, p22-phox C242T polymorphism, diabetes mellitus, calcium channel blockers use and angiotensin-converting enzyme inhibitors/angiotensin receptor blockers use as independent variables. Only variables with significant association were presented. LV - left ventricular.

the studied populations might have played a role in this regard. Conversely, although considered a stimulus for NADPH-oxidase activation $[8,26,28]$, PMA also induces mitochondrial release of reactive oxygen species [29], which could also account for the discrepant results. Here, evaluation of NADPH-oxidase activation was performed by treating mononuclear cells with DPI, which is considered a specific inhibitor of NADPH-oxidase [30], thus differing from the aforementioned studies. In addition, our findings agree with data showing increased superoxide production in transgenic HL-60 cells transfected with expression plasmids carrying p22-phox cDNAs with $\mathrm{C} 242 \mathrm{~T}$ polymorphism [8], thus strengthening the notion that this variant might induce gain of function for the NADPH-oxidase activity.

One limitation of this study is that part of hypertensive subjects was on medications. Some findings regarding

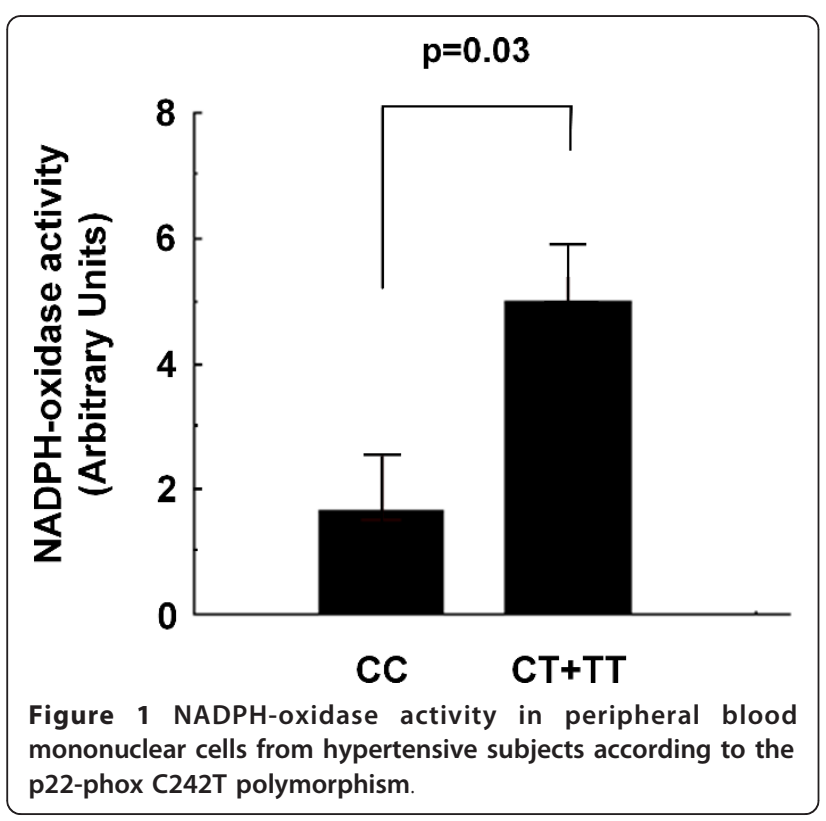

the impact of the polymorphism on LV mass might be, therefore, attributable to differential effect of various therapy regimens. However, we diminished this potential bias by considering in multivariate models the presence of antihypertensive medications. On the other hand, it should be acknowledged that some variables that may modulate LV remodeling, such as duration of hypertension and diabetes control, were not included in multivariate analysis. This might constitute another potential limitation to this study.

\section{Conclusions}

This study shows that genetic variation within p22-phox gene is significantly associated with higher LV mass in two independent Brazilian samples of hypertensive patients. A more complete understanding of the biochemical processes by which p22-phox alters myocardial growth may aid in unveiling how genetic variation in NADPH-oxidase components might modulate LV remodeling in hypertensive patients.

\section{Acknowledgements}

This work was supported by grants from Fundação de Amparo à Pesquisa do Estado de São Paulo (Proc. 2010/16252-0) and Conselho Nacional de Desenvolvimento Científico e Tecnológico (Proc. 474966/2010-0 and 474966/2010-0).

\section{Author details}

${ }^{1}$ Department of Internal Medicine, University of Campinas, Campinas, Brazil. ${ }^{2}$ Department of Clinical Pathology, University of Campinas, Campinas, Brazil. ${ }^{3}$ Federal University of Espírito Santo, Vitória, Brazil. ${ }^{4}$ Laboratory of Genetics and Molecular Cardiology, Heart Institute (InCor), University of São Paulo, São Paulo, Brazil.

\section{Authors' contributions}

RS carried out the molecular genetic studies, statistical analysis and drafted the manuscript. MCFS carried out the molecular genetic studies and participated in individual selection and characterization. JAR and AEV carried out the NADPH-oxidase activity assay. JAC and JGM were responsible for echocardiography studies. JAPM, JRMS, JEK and KGF participated in the design of the study and were responsible for individual selection and characterization. WNJ and ACP participated in the design of the study, 
statistical analysis and coordinated experiments and manuscript preparation. All authors read and approved the final manuscript.

\section{Competing interests}

The authors declare that they have no competing interests.

Received: 30 May 2011 Accepted: 31 August 2011

Published: 31 August 2011

\section{References}

1. Ruilope LM, Schmieder RE: Left ventricular hypertrophy and clinical outcomes in hypertensive patients. Am J Hypertens 2008, 21:500-508

2. Maytin M, Siwik DA, Ito M, Xiao L, Sawyer DB, Liao R, Colucci WS: Pressure overload-induced myocardial hypertrophy in mice does not require gp91phox. Circulation 2004, 109:1168-1171.

3. Murdoch CE, Zhang M, Cave AC, Shah AM: NADPH oxidase-dependent redox signalling in cardiac hypertrophy, remodelling and failure. Cardiovasc Res 2006, 71:208-215.

4. Ambasta RK, Kumar P, Griendling KK, Schmidt HH, Busse R, Brandes RP. Direct interaction of the novel Nox proteins with p22phox is required for the formation of a functionally active NADPH oxidase. J Biol Chem 2004, 279:45935-45941.

5. Nadruz W Jr, Lagosta VJ, Moreno H Jr, Coelho OR, Franchini KG: Simvastatin prevents load-induced protein tyrosine nitration in overloaded hearts. Hypertension 2004, 43:1060-1066.

6. Zalba G, San José G, Moreno MU, Fortuño A, Díez J: NADPH oxidasemediated oxidative stress: genetic studies of the p22(phox) gene in hypertension. Antioxid Redox Signal 2005, 7:1327-1336.

7. Dinauer MC, Pierce EA, Bruns GA, Curnutte JT, Orkin SH: Human neutrophil cytochrome b light chain (p22-phox). Gene structure, chromosomal location, and mutations in cytochrome-negative autosomal recessive chronic granulomatous disease. J Clin Invest 1990, 86:1729-1737.

8. Shimo-Nakanishi Y, Hasebe T, Suzuki A, Mochizuki H, Nomiyama T, Tanaka Yasushi, Nagaoka I, Mizuno Y, Urabe T: Functional effects of NAD (P)H oxidase p22(phox) C242T mutation in human leukocytes and association with thrombotic cerebral infarction. Atherosclerosis 2004, 175:109-115.

9. San José G, Fortuño A, Beloqui O, Díez J, Zalba G: NADPH oxidase CYBA polymorphisms, oxidative stress and cardiovascular diseases. Clin SCi 2008, 114:173-182.

10. Di Castelnuovo A, Soccio M, lacoviello L, Evangelista V, Consoli A, Vanuzzo D, Diviacco S, Carluccio M, Rignanese L, De Caterina R: The C242T polymorphism of the p22phox component of $\mathrm{NAD}(\mathrm{P}) \mathrm{H}$ oxidase and vascular risk. Two case-control studies and a meta-analysis. Thromb Haemost 2008, 99:594-601.

11. Sales ML, Schreiber R, Ferreira-Sae MC, Fernandes MN, Piveta C, Cipolli JA, Calixto A, Matos-Souza JR, Geloneze B, Franchini KG, Nadruz W Jr: The functional Toll-like receptor 4 Asp299Gly polymorphism is associated with lower left ventricular mass in hypertensive women. Clin Chim Acta 2010, 411:744-748

12. Sales ML, Schreiber R, Ferreira-Sae MC, Fernandes MN, Piveta CS, Cipolli JA, Cardoso CC, Matos-Souza JR, Geloneze B, Franchini KG, Nadruz W Jr: Tolllike Receptor 6 Ser249Pro polymorphism is associated with lower left ventricular wall thickness and inflammatory response in hypertensive women. Am J Hypertens 2010, 23:649-654.

13. Pereira AC, Pereira AB, Mota GF, Cunha RS, Herkenhoff FL, Pollak MR, Mill JG, Krieger JE: NPHS2 R229Q functional variant is associated with microalbuminuria in the general population. Kidney Int 2004, 65:1026-1030.

14. Executive Summary: The Third Report of The National Cholesterol Education Program (NCEP) Expert Panel on Detection, Evaluation And Treatment of High Blood Cholesterol in Adults (Adult Treatment Panel III). JAMA 2001, 285:2486-2497.

15. Pio-Magalhães JA, Cornélio M, Leme CA Jr, Matos-Souza JR, Garlipp CR, Gallani MC, Rodrigues RC, Franchini KG, Nadruz W Jr: Upper arm circumference is an independent predictor of left ventricular concentric hypertrophy in hypertensive women. Hypertens Res 2008, 31:1177-1183.

16. Cipolli JA, Souza FA, Ferreira-Sae MC, Pio-Magalhães JA, Figueiredo ES, Vidotti VG, Matos-Souza JR, Franchini KG, Nadruz W Jr: Sex-specific hemodynamic and non-hemodynamic determinants of aortic root size in hypertensive subjects with left ventricular hypertrophy. Hypertens Res 2009, 32:956-961

17. Lang RM, Bierig M, Devereux RB, Flachskampf FA, Foster E, Pellikka PA, Picard MH, Roman MJ, Seward J, Shanewise J, Solomon S, Spencer KT, St John Sutton M, Stewart W, American Society of Echocardiography's Nomenclature and Standards Committee, Task Force on Chamber Quantification, American College of Cardiology Echocardiography Committee, American Heart Association, European Association of Echocardiography, European Society of Cardiology: Recommendations for chamber quantification. Eur J Echocardiogr 2006, 7:79-108.

18. Inoue N, Kawashima S, Kanazawa K, Yamada S, Akita H, Yokoyama M: Polymorphism of the NADH/NADPH oxidase p22 phox gene in patients with coronary artery disease. Circulation 1998, 97:135-137.

19. Degasperi GR, Denis RGP, Morari J, Solon C, Geloneze B, Stabe C, Pareja JC, Vercesi $A E$, Velloso LA: Reactive oxygen species production is increased in the peripheral blood monocytes of obese patients. Metabolism 2009, 58:1087-1095.

20. Cahilly C, Ballantyne CM, Lim DS, Gotto A, Marian AJ: A variant of p22 (phox), involved in generation of reactive oxygen species in the vessel wall, is associated with progression of coronary atherosclerosis. Circ Res 2000, 86:391-395.

21. Ito D, Murata M, Watanabe K, Yoshida T, Saito I, Tanahashi N, Fukuuchi Y: C242T polymorphism of NADPH oxidase p22 PHOX gene and ischemic cerebrovascular disease in the Japanese population. Stroke 2000, 31:936-939.

22. Kim Kl, Na JE, Kang SY, Cho YS, Choi DJ, Kim CH, Kim HS, Oh BH, Choi YH, Kwon IS, Park SC: Impact of NAD(P)H oxidase p22 phox gene polymorphism on vascular aging in Korean centenarian and nonagenarian. Int J Cardiol 2007, 123:18-22.

23. Li A, Prasad A, Mincemoyer R, Satorius C, Epstein N, Finkel T, Quyyumi AA: Relationship of the C242T p22phox gene polymorphism to angiographic coronary artery disease and endothelial function. Am J Med Genet 1999, 86:57-61.

24. Fan $M$, Kähönen $M$, Rontu $R$, Lehtinen $R$, Viik J, Niemi M, Nieminen $T$, Niemelä K, Pörsti I, Kööbi T, Turjanmaa V, Lehtimäki T: The p22phox C242T gene polymorphism is associated with a reduced risk of angiographically verified coronary artery disease in a high-risk Finnish Caucasian population. The Finnish Cardiovascular Study. Am Heart 2006, 152:538-542

25. Hayaishi-Okano R, Yamasaki Y, Kajimoto Y, Sakamoto K, Ohtoshi $K$ Katakami N, Kawamori D, Miyatsuka T, Hatazaki M, Hazama Y, Hori M: Association of $\mathrm{NAD}(\mathrm{P}) \mathrm{H}$ oxidase p22 phox gene variation with advanced carotid atherosclerosis in Japanese type 2 diabetes. Diabetes Care 2003, 26:458-463.

26. Moreno MU, San Jose G, Fortuño A, Beloqui O, Diez J, Zalba G: The C242T CYBA polymorphism of NADPH oxidase is associated with essential hypertension. J Hypertens 2006, 24:1299-1306.

27. Sales ML, Ferreira MC, Leme CA Jr, Velloso LA, Gallani MC, Colombo RC, Franchini KG, Nadruz W Jr: Non-effect of p22-phox -930A/G polymorphism on end-organ damage in Brazilian hypertensive patients. J Hum Hypertens 2007, 21:504-506.

28. Wyche KE, Wang SS, Griendling KK, Dikalov SI, Austin H, Rao S, Fink B, Harrison DG, Zafari AM: C242T CYBA polymorphism of the NADPH oxidase is associated with reduced respiratory burst in human neutrophils. Hypertension 2004, 43:1246-1251.

29. Wang Y, Biswas G, Prabu SK, Avadhani NG: Modulation of mitochondrial metabolic function by phorbol 12-myristate 13-acetate through increased mitochondrial translocation of protein kinase Calpha in $\mathrm{C} 2 \mathrm{C} 12$ myocytes. Biochem Pharmacol 2006, 72:881-892.

30. Yang M, Foster E, Kahn AM: Insulin-stimulated NAD(P)H oxidase activity increases migration of cultured vascular smooth muscle cells. Am J Hypertens 2005, 18:1329-1334.

\section{Pre-publication history}

The pre-publication history for this paper can be accessed here: http://www.biomedcentral.com/1471-2350/12/114/prepub

doi:10.1186/1471-2350-12-114

Cite this article as: Schreiber et al:: The C242T polymorphism of the p22-phox gene (CYBA) is associated with higher left ventricular mass in Brazilian hypertensive patients. BMC Medical Genetics 2011 12:114. 